\title{
Amygdalin as a Plant-Based Bioactive Constituent: An Updated Substantial Review on Intervention with Gut Microbiota, Anticancer Mechanisms, Bioavailability, and Microencapsulation ${ }^{+}$
}

\author{
Hassan Barakat ${ }^{1,2}$ \\ 1 Department of Food Science and Human Nutrition, College of Agriculture and Veterinary Medicine, \\ Qassim University, Buraydah 51452, Saudi Arabia; haa.mohamed@qu.edu.sa or \\ hassan.barakat@fagr.bu.edu.eg; Tel.: +966-547141277 \\ 2 Food Technology Department, Faculty of Agriculture, Benha University, Moshtohor 13736, Qaliuobia, \\ Egypt \\ + Presented at the The 1st International Electronic Conference on Nutrients - Nutritional and Microbiota \\ Effects on Chronic Disease, 02-15 November 2020; Available online: https://iecn2020.sciforum.net/.
}

Published: 30 October 2020

\begin{abstract}
Amygdalin - a plant-based bioactive constituent particularly abundant in bitter almond has been identified as a symbol of cyanogenic glycoside chemical organic compound which originally intended to be a medication for cancer treatment once hydrolyzed to hydrogen cyanide (HCN). Unfortunately, studies have revealed that HCN can affect normal cells in a similar way, rendering it harmless to the human body. Both in vivo and in vitro investigations are extremely controversial and make its use unsafe. An updated substantial review on the source, structure, intervention with gut microbiota, anticancer therapy, bioavailability, and microencapsulation of amygdalin was summarized. Amygdalin provided anti-tumor, anti-fibrotic, anti-atherosclerosis, anti-inflammatory, immunomodulatory, analgesic, ameliorating digestive and reproductive systems, and enhancing neurodegeneration as well as myocardial hypertrophy. Studies confirmed that toxicity of amygdalin produced by its $\mathrm{HCN}$ after oral ingestion. However, the intravenous route of administration was much less than the oral route, and can be avoided with an oral dosage ranging from 0.6 to $1 \mathrm{~g}$ daily. The diversity of gut consortium is a key factor in inducing toxicity by amygdalin. Indeed, there is no guaranteed way to point out the microbial consortium for each person and provide a safe oral dosage. Recently, the encapsulating of amygdalin using alginatechitosan nanoparticles (ACNPs) as transporter was investigated. As an active drug delivery mechanism for regulated and constant release of amygdalin with its enhanced cytotoxic effect on cancerous cells, biocompatible and biodegradable ACNPs can be applied while protecting normal cells and tissues. In conclusion, still unproven and conflicting facts give way to a broad avenue of research for a compound that could potentially be the next stage of cancer therapy.
\end{abstract}

Keywords: amygdalin; anticancer therapy; mechanisms; gut microbiota; microencapsulation; and bioavailability

\section{Introduction}

Amygdalin is one of the major pharmacological components in almonds and normally available in the seeds of Rosaceae plants [1,2]. It is a widespread substance in the environment, occurring in seeds of many plants, including black cherries and apricots, etc. [3]. It is a cyanogenic glycoside chemical organic compound with a molecular formula of $\mathrm{C}_{20} \mathrm{H}_{27} \mathrm{O}_{11}$ (Figure 1A) and a molecular mass of $457.42 \mathrm{~g} \mathrm{~mol}^{-1}$. Amygdalin consists of benzaldehyde, hydrocyanic acid, and two glucose molecules 
(D-mandelonitrile- $\beta$-D-glucoside-6- $\beta$-glucoside), also known as Laeteile, which is derived mainly from almond, apricots, and apple seeds [4]. It has antioxidant, antibacterial, anti-inflammatory, and immunoregulatory functions [3]. Amygdalin is not a toxic substance but has toxic properties of HCN, produced during enzymatic hydrolysis. Years of studies on the effects of amygdalin have shown its efficient properties, including its supportive role in treating asthma, bronchitis, leprosy, or colorectal cancer [5,6]. It has analgesic effects due to the presence of benzaldehyde in its molecule [7]. However, its anticancer function is still controversial and consider a subject of more research. This capacity may be related to enzymatic hydrolysis, resulting in the release of hydrocyanic acid [8]. However, the use of amygdalin as an anticancer drug has been questioned due to its toxicity to normal cells and limited pharmacokinetic properties. The anticancerous effects are mainly considered to be apoptotic inducing cancer cell death, inhibiting the growth of cancer cells, by degrading carcinogenic compounds [9], blocking cancer cell's nutrient source thereby decreasing the incidence of multiple cancers [10]. The current review provides an updated substantial review on source, structure, intervention with gut microbiota, anticancer therapy, bioavailability, and microencapsulation of amygdalin as a plant-based bioactive constituent and its updated application in the field of dietetic therapy, hoping that updated data would offer theoretical and practical clues for exploring amygdalin's functional utility and applications in terms of its antitumor functionality.

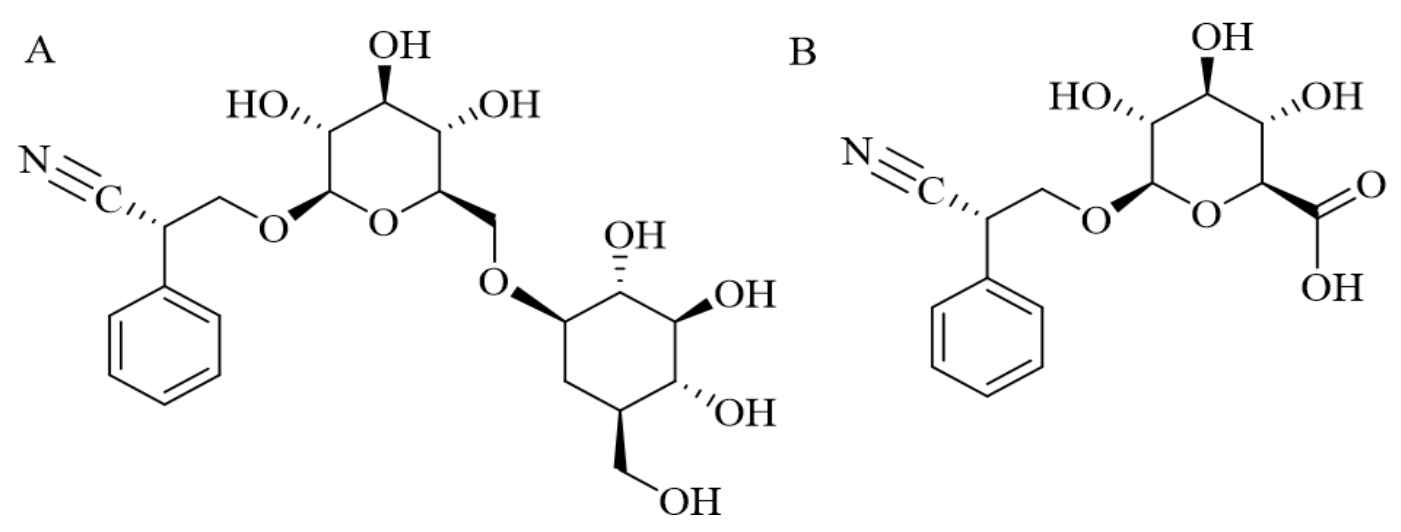

Figure 1. (A): Chemical structure of amygdalin, (B): Chemical structure of laetrile.

\section{The Microbiome and Oral amyGdalin Administration: Intervention with Gut Microbiota}

In the gastrointestinal tract (GIT), bacteria are extremely diverse and dominant, with about $10^{14}$ bacteria and 500 distinct species dominated by the anaerobes. Intestinal microbiota obtains their nutrition through the action of enzymes that produce such as sulfatase, esterase, $\alpha$-rhamnosidase, $\beta$ glucosidase, and $\beta$-glucuronidase by hydrolysis of sulfates, amides, glucuronidases, esters, and lactones [11]. Probiotics are organisms such as Lactobacillus and Bifidobacterium which help to modulate bacterial intestinal enzymes and absorb or bind carcinogenic substances. However, when amygdalin taken orally a drug is affected by lumen, gut wall, hepatic, and gut microbiome enzymes of GIT. Owing to minimal intestinal enzymatic activity, the undigested compounds flow down to the colon and specific digestion by gut microbial enzymes takes place. $\beta$-glucosidases present in kernels are also responsible for amygdalin hydrolysis [12]. Even the gut microflora determines the level of toxicity and the amount of whole blood cyanide [13]. They have high $\beta$-glucosidase activity, mainly the Bacteroides, and release cyanide via amygdalin symbiotic digestion. Different substrates have been shown for the intestinal and microbial $\beta$-glucosidases. Zhang et al. found that the gut microbiota of a termite-consuming polysaccharide had mainly members of the genus Bacteriodetes. They were found to be a rich source of $\beta$-glucosidase genes. Bacteriodetes have been shown to generate $\beta$ glucosidase enzyme also in the human intestine, which because of its work as a cellulose hydrolase plays an important role in hemicellulose or cellulose degradation [14]. Experiments on germ-free and control rats have shown that the gut microbiome induces the host to increase the production of glucose and tri-acyl glycerol [15]. This may explain why amygdalin, due to its glucose content, is strongly hydrolyzed. In obese and non-obese patients, it has been observed that, with a rise in body 
weight, the ratio of Bacteriodetes to Firmicutes decreases [16-18]. High-fiber diets such as those in Europe and rural Africa indicate a healthy population of Bacteriodetes in the gut [18]. This indicates that the interactions between diet, immune system, gut microbiota, and metabolism have significant effects on health and bacterial metabolism. Lactulose is also known to decrease the amount of $\beta$ glucosidase that generates Bacteriodetes [16]. Amygdalin is used as conventional and alternative medicine (CAM) therapy because the cyanide obtained on hydrolysis can bind to cytochrome oxidase $\mathrm{c}$ and $\mathrm{a} 3$, interfere with respiration and DNA synthesis due to reactive oxygen species formation, obstruct cell nutrition and lead to lysis $[19,20]$. This is useful for parenteral administration but will hit the gut unchanged upon ingestion. The gut microbiota is anaerobic, producing high levels of lactic acid through pyruvate fermentation [21]. This $\mathrm{pH}$ raises $\beta$-glucosidase activity because of which amygdalin is hydrolyzed to cyanide and contributes to toxicity. Blaheta et al., have shown that amygdalin still has anti-tumor properties in the absence of $\beta$-glucosidase, giving rise to the possibility that it is not the cyanide that is responsible for that effect [12]. It is suspected that by inhibiting collagenase and hyaluronidase, which weakens the matrix and contributes to benign tumors, the strength of the intracellular matrix into which cancer cells are embedded is increased [22,23]. Usually, these two CAM therapies are administered together. Huge doses of vit. $C$ are now notorious for depleting the body's cysteine reserves. Cysteine plays a role in thiocyanate formation in the ratelimiting stage [21]. Amygdalin can be hydrolyzed by gut bacteria, combined with the physiological effects of vit. C, resulting in increased exposure to cyanide [21]. The same is proven by studies by Ward et al. [24]. Studies have provided contradictory findings for use of both therapies alone and in combination. Some reveal that this may be due to oral intake rather than intravenous, which contributes to cyanide toxicity rather than cancer rectification [25]. Owing to the lack of $\beta$-glucosidase and the presence of Rhodanese, intravenous routes lead to low HCN levels. Big oral doses are hard to detoxify since there is little to no Rhodanese in the GIT [26]. It can be difficult to diagnose cyanide poisoning, and the study of arterial blood gas can be used for quick and effective prognosis [27]. Treatment for which a cyanide antidote kit was initially used after diagnosis is needed but it had its own toxicity issues. Cynokit (hydroxocobalamin) is widely used and there are no clinically relevant adverse effects other than chromaturia and discoloration of the red skin $[11,28]$. Due to the higher binding affinity, vitamin $\mathrm{B}_{12}$ can chelate cyanide, form cyanocobalamin, and leave the system through the kidneys [29]. Due to this property, it is used as a cyanide antidote [19]. Another alternative therapy may be probiotic ingestion, which is known to decrease Bacteroides levels. But it was understood that Lactobacillus develops $\beta$-glucosidases. Studies on HCN levels in a cancer patient with low Bacteriodetes and strong $\beta$-glucosidase generating amygdalin-ingested Lactobacillus need to be conducted further.

\section{Anti-Cancer Mechanisms of Amygdalin: A Molecular Approach}

Initially, amygdalin was intended to be a safe medication for cancer treatment and was accepted by natural medicine followers because it was believed to be hydrolyzed only in cancer cells releasing toxic HCN and therefore killed. Unfortunately, reviewed studies by Liczbiński et al. [30] shown that $\mathrm{HCN}$ is also produced in normal cells, so it may not be safe for human beings. However, scientific work on the anti-cancer properties of this compound has still been performed. In vitro studies have shown induction of apoptosis by amygdalin as a result of increased Bax protein and caspase- 3 expression and decreased antiapoptotic BcL-2protein expression. It has also been shown that amygdalin prevents the adhesion of breast cancer cells, lung cancer cells, and bladder cancer cells by decreasing integrin expression, reducing catenin levels, and inhibiting the Akt-mTOR pathway, which may result in inhibition of cancer cell metastases. It was also discovered that amygdalin increased the expression of p19 protein in renal cancer cells, resulting in inhibition of cell transfer from G1 to S-phase, and thus inhibited cell proliferation. Other studies have shown that amygdalin inhibits the signaling pathways of NF-kb and NLRP3 and thus has an anti-inflammatory effect due to decreased expression of pro-inflammatory cytokines such as pro-IL-1b. In addition, the effect of amygdalin on the TGFb/CTGF pathway, anti-fibrous activity, and follistatin expression resulting in muscle cell growth activation was recorded. This compound may contribute to the treatment of 
different types of cancer cells. On the other side, amygdalin might be used as an alternative therapy for bone fractures mediated by TGF-beta/Smad signaling [31] (Table 1).

Table 1. lists the key sources relating to its anti-inflammatory and analgesic activities.

\begin{tabular}{|c|c|c|c|}
\hline Model & Dose/method/period & Activity & Refs. \\
\hline BV2 glial cells & $\begin{array}{l}\text { 1, 10, } 100,1000 \mu \mathrm{g} \mathrm{mL}^{-1} \\
\text { culture; } 24 \mathrm{~h}\end{array}$ & $\begin{array}{l}\text { COX-2 mRNA, iNOS mRNA } \downarrow \\
\text { the synthesis of prostaglandin E2 } \downarrow \\
\text { the production of nitric oxide } \downarrow\end{array}$ & [32] \\
\hline RAW 264.7 cells & $\begin{array}{l}\text { 1, } 10,100 \mathrm{mmol} \mathrm{L}^{-1} \text {; } \\
\text { culture; } 6 \mathrm{~h}\end{array}$ & $\begin{array}{l}\text { At a concentration of } 1 \mathrm{mM} \text {, TNF- } \alpha \text { and IL- } 1 \beta \\
\text { mRNA } \downarrow \\
\text { Amygdalin does not inhibit TNF- } \alpha \text { and IL-1 } \beta \\
\text { mRNA expression in a dose-dependent manner. }\end{array}$ & [33] \\
\hline $\begin{array}{l}\text { Arthritis pain model } \\
\text { (Carrageenan-induced), SD } \\
\text { male rats }\end{array}$ & $\begin{array}{l}0.005,0.05 \text { and } 0.1 \mathrm{mg} \mathrm{kg}^{-1} \text {; } \\
\mathrm{im} ; 8 \mathrm{~h}\end{array}$ & $\begin{array}{l}\text { At a concentration of } 0.005 \mathrm{mg} / \mathrm{kg} \text {, Fos, TNF- } \alpha \\
\text { and } \\
\text { IL-1 } 1 \text {; However, no analgesic effect of } \\
\text { amygdalin was } \\
\text { observed at doses greater than } 0.005 \mathrm{mg} / \mathrm{kg} . \downarrow\end{array}$ & [33] \\
\hline $\begin{array}{l}\text { Pain model (plantar } \\
\text { injection of formalin), } \\
\text { SD male rats }\end{array}$ & $\begin{array}{l}0.1,0.5,1.0 \text { and } 10.0 \mathrm{mg} \\
\mathrm{kg}^{-1} \text {; Plantar injection }\end{array}$ & $\begin{array}{l}\text { c-Fos, TNF- } \alpha, \mathrm{IL}-1 \beta \\
\text { Laetrile reduces pain in a dose-dependent } \\
\text { manner in a dose range of less than } 1 \mathrm{mg} / \mathrm{kg} \text {. }\end{array}$ & [33] \\
\hline $\begin{array}{l}\text { CIA rat model (type II } \\
\text { collagen-induced), } \\
\text { Wistar rats }\end{array}$ & $\begin{array}{l}120 \mathrm{mg} \mathrm{kg}^{-1} \text {; gavage; } 28 \\
\text { days }\end{array}$ & TNF- $\alpha$ and sICAM- $1 \downarrow$ & [34] \\
\hline BALB/c mice & $0.5,1$ and $2 \mathrm{mg} \mathrm{kg}^{-1} ; \mathrm{ip} ; 7 \mathrm{~h}$ & $\begin{array}{l}\text { NF- } \kappa \mathrm{B} \downarrow \\
\text { Reduced pulmonary edema in a dose-dependent } \\
\text { manner. }\end{array}$ & [35] \\
\hline RAW264.7 cells & $\begin{array}{l}6.25,12.5,25,50,100,200 \\
400 \mu \mathrm{mol} \mathrm{L}-1 ; \text { culture; } 24 \mathrm{~h}\end{array}$ & $\begin{array}{l}\text { IL-17A, IL-23, CCL2 and CCL5 mRNA } \downarrow \text { p-p38 } \downarrow \\
\text { the viability of RAW264.7 cell } \downarrow\end{array}$ & [36] \\
\hline
\end{tabular}

\section{Microencapsulation and Bioavailability}

The anticancerous activities of amygdalin are mostly measured to be apoptotic persuading cancer cell death, hindering the cancer cell's growth, by debasing carcinogenic components [9], hindering cancer cell's nutrient thus declining the multiple cancers incidence [10]. It has been utilized for asthma, bronchitis, emphysema, leprosy, colorectal cancer, and vitiligo, and multiple cancers treatment [5]. However, using of amygdalin as an anticancer drug has been quizzed owing to its toxicity to normal cells and imperfect pharmacokinetic belongings. Amygdalin has only been utilized hardly and has not been explored yet with any drug delivery nanocarriers. To upsurge the therapeutic activities and decrease side-effects of amygdalin, the encapsulation of amygdalin is needed. Nanocarriers as smart drug delivery systems are being designed, developed, and investigated for many applications including therapeutics [37]. Nanoparticulate drug delivery has exposed to vastly rise therapeutic activity duration, drug-stability, allowing drug's parent or enteral administration, cumulative drug penetrability, thus minimizing or preventing drug metabolism, cellular efflux as well as squalor [38]. Nanoparticles $(1-200 \mathrm{~nm})$ are usually laden with drugs by either in core-encapsulation or by surface adsorption. Besides metallic, normal degradable biopolymers, polysaccharides, synthetic polymers, and lipids are being utilized in making nanoparticles. Colloidal polymeric nanoparticles, besides their small size, can deliver constant drug release over time owing to possible adapt made alignment [39]. Furthermore, biodegradability, nontoxicity, biocompatibility, low-cost, and high-abundance in nature rise their usage in making drug delivery systems [40]. Amygdalin, despite having anticancerous features, has been observed as a contentious optimal due to the attendance of the cyanide group. The potential of alginate-chitosan nanoparticles (ACNPs) as drug delivery agents for amygdalin encapsulation and its delivery to cancer cells were investigated [37], Amygdalin-ACNPs loaded were made with anionic and/or cationic outer layer to extra explore charge dependence on drug delivery and cytotoxicity. ACNPs-encapsulating amygdalin was monodispersing, colloidally stable by $90 \%$ drug encapsulation efficacy, and was wholly ended from natural ingredients. The nanoparticles showed constant drug release for a period of $10 \mathrm{~h}$ and significant bump rates in neutral and somewhat acidic settings. The ACNPs positively obeyed to 
porcine mucin type II when measured for its muco-adhesion and exposed to drift with an average velocity of $1.68 \mu \mathrm{m} \mathrm{s}^{-1}$ in uncoated channels, under bio-mimicked flow circumstances. To examine charge dependence on drug delivery and cytotoxicity, amygdalin loaded ACNPs were ended with both anionic and cationic outer layer and measured. ACNPs demonstrated better yet sustained anticancerous activity on H1299-cells in a dose-dependent manner than free-amygdalin signifying better cellular approval of the previous. The author was demonstrated that stable anionic and cationic surface amygdalin-loaded-ACNPs can be synthesized by ionic gelation method with high colloidal stability as publicized by its zeta potential ( -36 and +32 ) having a size of $\sim 119 \mathrm{~nm}$ and high drug encapsulation efficiency [37]. ACNPs presented amplified swelling and sustained drug release shape with $\mathrm{pH}(3.1,5.0,7.4)$. The amygdalin-loaded-ACNPs exhibited effectual passage under 10 dynes $\mathrm{cm}^{-2}$ shear flow stress and good mucoadhesive property in the BioFlux system. Finally, the author proposed ACNPs as an active drug delivery carrier for amygdalin, present sustain release, and better efficacy and delivery. This inspires further in-vivo analysis of the prepared amygdalin-loaded ACNPs on cancer tumour models. Recently, Zhou et al. [41] showed that by chemical coupling methods, starch-coated magnetic nanoparticles (MNPs) were successively conjugated with $\beta$ glucosidase $(\beta-\mathrm{Glu})$ and polyethylene glycol (PEG). Consequently, amygdalin-mediated immobilized $\beta$-Glu activated prostate cancer cell death. Tumor-targeting studies have shown that PEG modification has increased the accumulation of nanoparticles loaded with $\beta$-Glu in targeted tumor tissue subjected to an external magnetic field and decreased the accumulation of nanoparticles in the liver and spleen. Protection analyses found that this technique had some effect on the function of the liver and heart, but did not cause obvious organ damage. All results suggest that this technique of magnetically directed enzyme/prodrug therapy has the potential to become a promising new method for prostate cancer targeted therapy.

\section{Future Perspectives and Conclusions}

Amygdalin has customarily been used for cough, asthma, leprosy, bronchitis, nausea, and leukoderma treatment. Earlier in vivo and in vitro researches have authenticated its pharmacological effects of anti-tumor, anti-fibrotic, anti-inflammatory, analgesic, immunomodulatory, antiatherosclerosis, ameliorating peptic system and reproductive, refining neurodegeneration and myocardial hypertrophy, as well as falling blood glucose. But the obtainable research has mostly fixated on the pharmacological activity and toxicity of amygdalin and the clarification about the molecular mechanisms of its actions are still inadequate. Studies are extremely controversial, rendering it hazardous for use as a therapeutic agent. Neither systemic data concerning the pharmacokinetics of amygdalin nor estimations of its target-organ toxicity have been sufficiently known. Hence, more novel research needs to be directed in the future to assess its possible therapeutic effects, side effects, or toxicity. Moreover, in recent years, cumulative but still only an imperfect number of studies have fixated on its effect on inflammation, digestion, neurodegeneration, reproduction, myocardial hypertrophy, and blood glucose, more studies want to be achieved to obtain a more complete understanding of this component. Current literature points to the fact that amygdalin causes toxicity on oral consumption and not i.v. administration but, its mode of action and toxicity causing dose is still not confirmed and gut consortium-dependent. Amygdalin has only been used barely and has not been widley investigated yet with any drug delivery nanocarriers, in vivo. Recent experiments using amygdalin-loaded ACNPs and an amygdalin/ $\beta$-Glu-based MDEPT strategy may have good prospects as promissing studies for clinical use in cancer therapies. Therefore, studies investigating its encapsulation and anticancerous efficacy in the encapsulated form to increase the therapeutic effect and reduce side-effects of amygdalin should be focused, further.

Funding: This research received no external funding. 


\section{References}

1. Jaswal, V.; Palanivelu, J.; Ramalingam, C. Effects of the gut microbiota on amygdalin and its use as an anticancer therapy: Substantial review on the key components involved in altering dose efficacy and toxicity. Biochem. Biophys. Rep. 2018, 14, 125-132.

2. Toomey, V.M.; Nickum, E.A.; Flurer, C.L. Cyanide and amygdalin as indicators of the presence of bitter almonds in imported raw almonds. J. Forensic Sci. 2012, 57, 1313-1317.

3. Orlikova, B.; Legrand, N.; Panning, J.; Dicato, M.; Diederich, M. Anti-inflammatory and anticancer drugs from nature. In Advances in Nutrition and Cancer, Springer: Berlin/Heidelberg, Germany, 2014; pp. 123-143.

4. Qadir, M.; Fatima, K. Review on pharmacological activity of amygdalin. Arch. Cancer Res. 2017, 5, 160.

5. Li, X.-B.; Liu, C.-H.; Zhang, R.; Huang, X.-T.; Li, Y.-Y.; Han, L.; Xu, M.-L.; Mi, S.-Q.; Wang, N.-S. Determination and Pharmacokinetics of Amygdalin in Rats by LC-MS-MS. J. Chromatogr. Sci. 2014, 52, 476481.

6. Song, Z.; Xu, X. Advanced research on anti-tumor effects of amygdalin. J. Cancer Res. Ther. 2014, 10, 3.

7. Chang, H.-K.; Shin, M.-S.; Yang, H.-Y.; Lee, J.-W.; Kim, Y.-S.; Lee, M.-H.; Kim, J.; Kim, K.-H.; Kim, C.-J. Amygdalin induces apoptosis through regulation of Bax and Bcl-2 expressions in human DU145 and LNCaP prostate cancer cells. Biol. Pharm. Bull. 2006, 29, 1597-1602.

8. Zhou, C.; Qian, L.; Ma, H.; Yu, X.; Zhang, Y.; Qu, W.; Zhang, X.; Xia, W. Enhancement of amygdalin activated with $\beta$-D-glucosidase on HepG2 cells proliferation and apoptosis. Carbohydr. Polym. 2012, 90, 516523.

9. Park, H.-J.; Yoon, S.-H.; Han, L.-S.; Zheng, L.-T.; Jung, K.-H.; Uhm, Y.-K.; Lee, J.-H.; Jeong, J.-S.; Joo, W.-S.; Yim, S.-V. Amygdalin inhibits genes related to cell cycle in SNU-C4 human colon cancer cells. World J. Gastroenterol. WJG 2005, 11, 5156.

10. Chen, Y.; Ma, J.; Wang, F.; Hu, J.; Cui, A.; Wei, C.; Yang, Q.; Li, F. Amygdalin induces apoptosis in human cervical cancer cell line HeLa cells. Immunopharmacol. Immunotoxicol. 2013, 35, 43-51.

11. Ushakova, N.; Nekrasov, R.; Pravdin, I.; Sverchkova, N.; Kolomiyets, E.; Pavlov, D. Mechanisms of the effects of probiotics on symbiotic digestion. Biol. Bull. 2015, 42, 394-400.

12. Blaheta, R.A.; Nelson, K.; Haferkamp, A.; Juengel, E. Amygdalin, quackery or cure? Phytomedicine 2016, 23, 367-376.

13. Tokpohozin, S.E.; Fischer, S.; Sacher, B.; Becker, T. $\beta$-d-Glucosidase as "key enzyme" for sorghum cyanogenic glucoside (dhurrin) removal and beer bioflavouring. Food Chem. Toxicol. 2016, 97, 217-223.

14. Zhang, M.; Liu, N.; Qian, C.; Wang, Q.; Wang, Q.; Long, Y.; Huang, Y.; Zhou, Z.; Yan, X. Phylogenetic and functional analysis of gut microbiota of a fungus-growing higher termite: Bacteroidetes from higher termites are a rich source of $\beta$-glucosidase genes. Microb. Ecol. 2014, 68, 416-425.

15. Sorbo, B. On the properties of rhodanese: Partial Purification, Inhibitors and Intracellular Distribution. Acta Chem. Scand. 1951, 5, 724-726.

16. Duda-Chodak, A.; Tarko, T.; Satora, P.; Sroka, P. Interaction of dietary compounds, especially polyphenols, with the intestinal microbiota: A review. Eur. J. Nutr. 2015, 54, 325-341.

17. Greenberg, D.M. The vitamin fraud in cancer quackery. West. J. Med. 1975, 122, 345.

18. Chong, E.S.L. A potential role of probiotics in colorectal cancer prevention: Review of possible mechanisms of action. World J. Microbiol. Biotechnol. 2014, 30, 351-374.

19. Kuugbee, E.D.; Shang, X.; Gamallat, Y.; Bamba, D.; Awadasseid, A.; Suliman, M.A.; Zang, S.; Ma, Y.; Chiwala, G.; Xin, Y. Structural change in microbiota by a probiotic cocktail enhances the gut barrier and reduces cancer via TLR2 signaling in a rat model of colon cancer. Dig. Dis. Sci. 2016, 61, 2908-2920.

20. Bromley, J.; Hughes, B.G.; Leong, D.C.; Buckley, N.A. Life-threatening interaction between complementary medicines: Cyanide toxicity following ingestion of amygdalin and vitamin C. Ann. Pharmacother. 2005, 39, 1566-1569.

21. Padayatty, S.J.; Sun, A.Y.; Chen, Q.; Espey, M.G.; Drisko, J.; Levine, M. Vitamin C: Intravenous use by complementary and alternative medicine practitioners and adverse effects. PLoS ONE 2010, 5, e11414.

22. Richards, E. The politics of therapeutic evaluation: The vitamin C and cancer controversy. Soc. Stud. Sci. 1988, 18, 653-701.

23. Calabrese, E.J. Conjoint use of laetrile and megadoses of ascorbic acid in cancer treatment: Possible side effects. Med. Hypotheses 1979, 5, 995-997.

24. Ward, E.; Jemal, A.; Cokkinides, V.; Singh, G.K.; Cardinez, C.; Ghafoor, A.; Thun, M. Cancer disparities by race/ethnicity and socioeconomic status. CA A Cancer J. Clin. 2004, 54, 78-93. 
25. Holstege, C.P.; Forrester, J.D.; Borek, H.A.; Lawrence, D.T. A case of cyanide poisoning and the use of arterial blood gas analysis to direct therapy. Hosp. Pract. 2010, 38, 69-74.

26. Kleessen, B.; Sykura, B.; Zunft, H.-J.; Blaut, M. Effects of inulin and lactose on fecal microflora, microbial activity, and bowel habit in elderly constipated persons. Am. J. Clin. Nutr. 1997, 65, 1397-1402.

27. Borron, S.W.; Baud, F.J.; Mégarbane, B.; Bismuth, C. Hydroxocobalamin for severe acute cyanide poisoning by ingestion or inhalation. Am. J. Emerg. Med. 2007, 25, 551-558.

28. Oyewole, O.; Olayinka, E. Hydroxocobalamin (vit b12a) effectively reduced extent of cyanide poisoning arising from oral amygdalin ingestion in rats. J. Toxicol. Environ. Health Sci. 2009, 1, 008-011.

29. Chan, T.Y. A probable case of amygdalin-induced peripheral neuropathy in a vegetarian with vitamin B12 deficiency. Ther. Drug Monit. 2006, 28, 140-141.

30. Liczbiński, P.; Bukowska, B. Molecular mechanism of amygdalin action in vitro: Review of the latest research. Immunopharmacol. Immunotoxicol. 2018, 40, 212-218.

31. Ying, J.; Ge, Q.; Hu, S.; Luo, C.; Lu, F.; Yu, Y.; Xu, T.; Lv, S.; Zhang, L.; Shen, J., et al. Amygdalin Promotes Fracture Healing through TGF-beta/Smad Signaling in Mesenchymal Stem Cells. Stem Cells Int. 2020, 2020, 8811963, doi:10.1155/2020/8811963.

32. Yang, H.-Y.; Chang, H.-K.; Lee, J.-W.; Kim, Y.-S.; Kim, H.; Lee, M.-H.; Shin, M.-S.; Ham, D.-H.; Park, H.-K.; Lee, H., et al. Amygdalin suppresses lipopolysaccharide-induced expressions of cyclooxygenase-2 and inducible nitric oxide synthase in mouse BV2 microglial cells. Neurol. Res. 2007, 29, 59-64, doi:10.1179/016164107X172248.

33. Hwang, H.-J.; Lee, H.-J.; Kim, C.-J.; Shim, I.; Hahm, D.-H.J.J.M.B. Inhibitory effect of amygdalin on lipopolysaccharide-inducible TNF-alpha and IL-1beta mRNA expression and carrageenan-induced rat arthritis. J. Microbiol. Biotechnol. 2008, 18, 1641-1647.

34. Luo, D.; Shan, Z.; Jinlian, G.; Liu, Q.; Luo, L. Effects of Amygdalin on TNF- $\alpha$ and sICAM-1 of Rats with Type II Collagen-induced Arthritis. Chin. J. Inf. Tradit. Chin. Med. 2015,7, 75-77.

35. Zhang, A.; Pan, W.; Lv, J.; Wu, H. Protective effect of amygdalin on LPS-induced acute lung injury by inhibiting NF- $\mathrm{BB}$ and NLRP3 signaling pathways. Inflammation 2017, 40, 745-751.

36. Zhong, X.Q.; Li, L.; Lu, C.J.; Lu, Y.; Wei, J.A.; Han, L. Anti-inflammation Effect of Amygdalin on Macrophage 264.7 Cells Stimulated by Lipopolysaccharide. Tradit. Chin. Drug Res. Clin. Pharmacol. 2018, 29, 257-263.

37. Sohail, R.; Abbas, S.R. Evaluation of amygdalin-loaded alginate-chitosan nanoparticles as biocompatible drug delivery carriers for anticancerous efficacy. Int. J. Biol. Macromol. 2020, 153, 36-45, doi:10.1016/j.ijbiomac.2020.02.191.

38. Sarmento, B.; Ribeiro, A.; Veiga, F.; Ferreira, D.; Neufeld, R. Insulin-loaded nanoparticles are prepared by alginate ionotropic pre-gelation followed by chitosan polyelectrolyte complexation. J. Nanosci. Nanotechnol. 2007, 7, 2833-2841.

39. De Jong, W.H.; Borm, P.J. Drug delivery and nanoparticles: Applications and hazards. Int. J. Nanomed. 2008, $3,133$.

40. Liu, Z.; Jiao, Y.; Wang, Y.; Zhou, C.; Zhang, Z. Polysaccharides-based nanoparticles as drug delivery systems. Adv. Drug Deliv. Rev. 2008, 60, 1650-1662.

41. Zhou, J.; Hou, J.; Rao, J.; Zhou, C.; Liu, Y.; Gao, W. Magnetically Directed Enzyme/Prodrug Prostate Cancer Therapy Based on beta-Glucosidase/Amygdalin. Int. J. Nanomed. 2020, 15, 4639-4657, doi:10.2147/IJN.S242359.

Publisher's Note: MDPI stays neutral with regard to jurisdictional claims in published maps and institutional affiliations.

(C) 2020 by the authors. Submitted for possible open access publication under the terms and conditions of the Creative Commons Attribution (CC BY) license (http://creativecommons.org/licenses/by/4.0/). 